\title{
Rotational stress influences sensitized, but not habituated, exploratory behaviors in the woodlouse, Porcellio scaber
}

\author{
Patrick Anselme ${ }^{1}$
}

Published online: 5 February 2018

(C) Psychonomic Society, Inc. 2018

\begin{abstract}
Terrestrial isopods (or woodlice), like the members of the other arthropod taxa, have a sophisticated nervous system that makes them sensitive to specific environmental factors. They can search for survival-related opportunities (e.g., approaching food sources or avoiding sunny areas). Two experiments examined how rotational stress could influence the propensity of common woodlice, Porcellio scaber to exhibit survival-related behaviors such as traveling and rearing up in a hostile environment. Experiment 1 assessed the behaviors of stressed and nonstressed woodlice exposed to a familiar or a novel environment without rewards. Experiment 2 assessed the effects of stress in woodlice given a free choice between a familiar and a novel environment without rewards. In the nonstressed individuals, the results showed a decrease in locomotor activity (habituation) and an increase in the time spent rearing up (sensitization) on the arena's walls over time. In the stressed individuals, repeated rotation had a detrimental effect on the time spent rearing up, but locomotion was decreased only in the stressed individuals that were not preexposed to the test environment beforehand. In addition, immobilization periods - as a plausible indicator of stress-were longer in the absence of preexposure. It is suggested that preexposure had some antistress protective effects on habituated but not on sensitized, exploratory behaviors in woodlice.
\end{abstract}

Keywords Behavior $\cdot$ Exploration $\cdot$ Stress $\cdot$ Woodlice

Owing to the quasirandom distribution of resources in the environment, animals have to explore their local habitat in order to discover while actively avoiding the encounter of dangerous situations. In rodents, exploration is often measured as locomotion and rearing up in an open field, novelty-induced place preference, or object manipulation (e.g., Bardo, Neisewander, \& Pierce, 1989; Heyser \& Chemero, 2012; Kalueff, Keisala, Minasyan, Kuuslahti, \& Tuohimaa, 2006). The search for survival-related opportunities (or exploration) is not specific to mammalian and avian species (e.g., Hughes, 2007; Winkler \& Leisler, 1999), but also occurs in many invertebrate taxa through behaviors such as locomotion, antenna movements, and rearing up (e.g., Alcaro, Panksepp, \& Huber, 2011; Anselme, 2013b; Jander, 1997; Mailleux, Devigne, Deneubourg, \& Detrain, 2010; Mather \& Anderson, 1999).

Patrick Anselme

Patrick.Anselme@rub.de

1 Faculty of Psychology, Department of Biopsychology, University of Bochum, 150 Universitätsstraße, D-44801 Bochum, Germany
Does the encounter of stressors (predators, odors, noises, etc.) impact exploratory activity? A stress response is typically produced when individuals experience environmental conditions outside of their normal and/or safe perceptual range (Elwood, Barr, \& Patterson, 2009). In vertebrates, the physiological stress response consists of an activation of the hypothalamus-pituitary-adrenocortical axis (Cabib \& Puglisi-Allegra, 2012), which may lead to the release of glucocorticoid hormones such as cortisol and corticosterone. The consequences of glucocorticoids on exploratory activity depend on the species and the situation (Grønli et al., 2005; Harris, Zhou, Youngblood, Smagin, \& Ryan, 1998; Pravosudov, 2003; Strekalova, Spanagel, Bartsch, Henn, \& Gass, 2004). Invertebrates also react to environmental stressors, causing a physiological stress response that has common features with that observed in vertebrates (Elwood et al., 2009; Ottaviani \& Franceschi, 1996; Stefano et al., 2002). In crustaceans, the hyperglycemic hormone is the physiological marker of a stress response; this hormone plays a role similar to cortisol and corticosterone. The behavioral and physiological reactions observed are also mixed, dependent on the species and the stressor involved (e.g., Adamo \& 
Baker, 2011; Bateson, Desire, Gartside, \& Wright, 2011; Mailleux et al., 2010; Zhukovskaya, 2014).

Although the existence of physiological stress responses in invertebrates is now a well-established fact, the question of whether the members of invertebrate species can experience conscious feelings related to these physiological stress responses remains controversial (Barron \& Klein, 2016; Elwood et al., 2009; Mason, 2011; Mendl, Paul, \& Chittka, 2011). In this study, I do not aim to enrich this debate one way or the other. I use the word stressor to denote a form of stimulation outside of the normal perceptual range of woodlice, and the word stress to denote the behavioral reactions that result from exposure to that supernormal stimulation.

This article examines the behavioral effects of rotationinduced stress (e.g., Romana-Souza et al., 2010) on distance traveled and rearing-up behavior in woodlice, Porcellio scaber (Crustacea; Isopoda; Oniscidea). Woodlice are typically more active during the night and spend most of their time sheltering during the day (Drahokoupilová \& Tuf, 2012; Tuf \& Jeřábková, 2008). Humidity is a critical factor governing the dispersal of woodlice in their environment (Hornung, 2011), in addition to other factors such as food quality (Hassall, 1996; Zimmer \& Topp, 1997) and shelter quality (Anselme, 2013a; Hornung, 1991). Although the time allocated to exploration is limited in woodlice (Broly, Deneubourg, \& Devigne, 2013), seeking vital resources may motivate them to move away from their shelter. Here, rotation-induced shaking is viewed as a way of modeling physical disturbance for woodlice, resulting from foraging behaviors of a blackbird or a hedgehog seeking bugs under leaves and pieces of wood in a forest. Experiment 1 examined the effects of rotational stress on locomotion and rearing-up activity in a familiar or a novel environment without rewards. Experiment 2 studied the effects of rotational stress on the same exploratory behaviors when woodlice are given a free choice between a familiar and a novel environment without rewards. To allow them to discriminate between the two environments (familiar and novel), I used visual and tactile patterns that fall in the range of detectable sensory stimulations in these animals (see also Anselme, 2013a, 2013b, 2015). Woodlice can detect black/ light contrasts (Meyer-Rochow, 2001), and could even see under low light intensities (Nilsson \& Nilsson, 1981). Also, woodlice have a number of mechanoreceptors all over their cuticle and antenna-in addition to hygroreceptors and chemoreceptors - allowing them to detect small changes in the texture of the surfaces they encounter (Hoese, 1989; Holdich \& Lincoln, 1974; Powell \& Halcrow, 1982; Schmalfuss, 1998; Ziegler \& Altner, 1995). Given that woodlice show limited exploration of their surroundings and that individuals from the Porcellio genus typically react to stressors by adopting clinging behavior (Schmalfuss, 1984), it was predicted that rotational stress should decrease any kind of exploratory activity.

\section{Experiment 1}

The effects of rotation-induced stress on the distance traveled and rearing-up behavior were assessed in a familiar or a novel homogenous environment without rewards.

\section{Method}

\section{Animals and housing conditions}

Woodlice $(N=45$; size: $11.06 \pm 0.03 \mathrm{~mm})$ were collected in the author's garden, irrespective of their sex. Four batches of a maximum of 10 individuals were successively housed. They were kept for $24 \mathrm{hr}$ in a plastic container $(20 \mathrm{~cm} \times 12 \mathrm{~cm} \times 8 \mathrm{~cm})$ provided with earth, organic matter (leaves, small roots), and pieces of bark for sheltering. The soil was moderately humidified with rain water previously collected. The upper part of the container was open in order to allow for its ventilation. The woodlice were exposed to natural photoperiod. Following this 24$\mathrm{hr}$ period, the woodlice were tested (temperature: $23^{\circ} \mathrm{C}$; relative humidity: $48 \%$; brightness: $1,500 \mathrm{~lx}$ ), and then released. No mortality occurred during housing and observations. This research was conducted in Belgium and complied with the Federal Public Health Service, Food Chain Safety, and Environment requirements.

\section{Apparatus}

The apparatus was constructed from transparent Plexiglas and comprised five alleys $(30 \mathrm{~cm} \times 4 \mathrm{~cm} \times 4 \mathrm{~cm})$. Each alley consisted of two compartments $(14 \mathrm{~cm} \times 4 \mathrm{~cm} \times 4$ $\mathrm{cm})$ separated by an intermediate area $(2 \mathrm{~cm} \times 4 \mathrm{~cm} \times 4$ $\mathrm{cm})$. A removable divider $(2 \mathrm{~cm} \times 4 \mathrm{~cm} \times 4 \mathrm{~cm})$ was placed in the intermediate area of each alley in order to obtain a total of 10 compartments (see Fig. 1). All compartments contained a floor that consisted of a sheet of smooth paper, which was uniformly light brown. Floor materials were not reused. Each side (lateral, front, and back) of an alley was composed of two transparent vertical surfaces separated by $0.5 \mathrm{~cm}$, allowing the type of wall to be changed when necessary (cf. Experiment 2). Paper sheets of a darker brown color were placed between the two vertical surfaces forming the sides of each compartment. The removable dividers were made of wood and covered with adhesive transparent tape in order to prevent the woodlice from climbing out of the apparatus. The apparatus' upper part remained open, and a digital camera (Sony DCR-SX21) equipped with a stand and directed towards the room's floor ( $80 \mathrm{~cm}$ above the apparatus) filmed the 10 compartments simultaneously. 


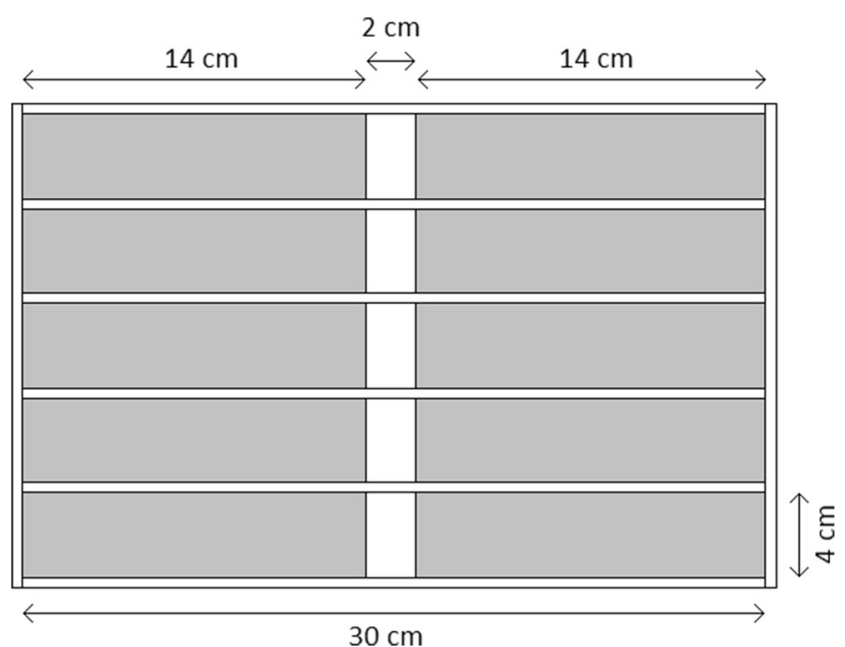

Fig. 1 Design of the experimental apparatus (seen from top)

\section{Procedure}

Up to 10 woodlice (one per compartment) could be tested at the same time, and they were subjected to a single session. Each woodlouse was gently placed in the center of each compartment and could freely move within that compartment for about $15 \mathrm{~min}$. The woodlice were filmed for $2 \mathrm{~min}$ at several points in time, depending on the conditions to which they were exposed. Three groups were assessed. In group Stress $(n=15)$, prior to their placement in the compartments, the woodlice were subjected to repeated rotation. For that, five plastic cups, with one woodlouse in each, were manually taken together (one finger per cup) and given a circular rotation at the speed of approximately three rotations per second for 10 seconds - the experimenter's arm acting as a fixed axis of rotation. This means that the woodlice were mildly centrifuged within the plastic cups. Then, any movements stopped for 2-3 s, and the same treatment was repeated in the reverse direction. This operation was repeated five times, for a total duration of approximately $2 \mathrm{~min}$. The agitated woodlice met no obstacle during centrifugation, limiting the risk of injury. Indeed, they have a robust armor protecting them against shocks, and they showed no evidence of physical injurysuch as a loss of antennae or of legs. In group No-Stress ( $n$ $=15$ ), the woodlice were immediately transferred to the apparatus' compartments by means of a plastic cup. They were tested in the same environmental conditions as the woodlice from group Stress. In these two groups, the stressed and nonstressed woodlice were exposed to a novel environment - and their behavior was recorded at min $0-1,5-6$, $10-11$, and 15-16. However, it was also necessary to determine how stress can influence their activity in a familiar environment. In group Pre/Post $(n=15)$, the woodlice were immediately transferred to the apparatus' compartments for 15 min (like in group No-Stress), were then subjected to the repeated rotation procedure described above, and were finally reexposed to the compartments for $2 \mathrm{~min}$. Their behavior was recorded during the $2 \mathrm{~min}$ that preceded (PRE) and followed (POST) repeated rotation. Five hours later, the activity of the woodlice from the first two groups was reassessed for two minutes in the same environment. The goal of this additional manipulation was twofold: (i) controlling activity level for possible injuries caused by rotations and (ii) providing an activity baseline in each group. Measuring the activity baseline after recovery from the stressful experience - rather than before the test-avoided any risk of habituation to the compartments. During the 5-hr recovery period, the woodlice were placed in the housing environment.

\section{Statistical analysis}

The exploratory behaviors examined were the distance traveled, the time spent rearing up on a compartment's walls, and the number of rearing-up behaviors displayed. Distance traveled was assessed by means of a grid whose size was that of a compartment and which was applied at the flat screen of a computer. The number of squares (corresponding to $1 \mathrm{~cm} \times 1$ $\mathrm{cm}$ ) crossed by the woodlice was counted. Distance traveled is an indicator of exploratory activity, including in crustaceans (Huber, Panksepp, Nathaniel, Alcaro, \& Panksepp, 2011). A woodlouse reared up on a wall when the anterior part (at least the first half) of its body was in contact with the wall. The woodlouse was then in (close to) a vertical orientation. This behavior is also a good indicator of exploratory activity in crustaceans and other zoological groups (Anselme, 2015; Huber et al., 2011; Hughes, 1968). Time was measured using a manual digital stopwatch and compared against the data collected with the video monitor's timer for more reliability. The analyses were based on manual measurements. P. scaber is classified as a "clinger" because it tends to respond to a mechanical stimulation by adhering closely to the substrate (Schmalfuss, 1984). Because this behavior might be an indicator of stress, I checked the time spent immobile and the number of immobilization periods during the first 2 minutes in groups Stress and No-Stress, and before and after treatment in group Pre/Post. (Note that one individual from group Stress was removed from analysis because it had been on its back most of the time.) In order to avoid including short immobilization periods caused by directional changes and apparent hesitations with respect to the direction to follow, I only considered immobilizations longer than $3 \mathrm{~s}$. The values associated with these behavioral parameters were all extracted from videos one by one (no multiple measurements). $T$ tests were used as appropriate, and mixed ANOVAs (two-tailed) were carried out for between-subjects and within-subjects comparisons (Statistica 12). Two data sets were assessed by means of planned comparisons. Repeated measures were used for comparisons involving the same animals. The null hypothesis was rejected at $p<.05$. All measurements are indicated as mean $\pm S E$. 


\section{Results}

\section{Novel environment (groups Stress and No-Stress)}

As depicted in Fig. 2a, the distance traveled by the woodlice decreased over the 15 -min period. There was a significant effect of group and time, group: $F(1,28)=4.589, p=.041$; time: $F(3,84)=4.547, p=.005$, but only a nonsignificant trend for Group $\times$ Time interaction, $F(3,84)=2.353, p=.078$. Specifically, during the first 2 and the last 2 minutes, the stressed woodlice traveled a shorter distance than the nonstressed individuals, $0-1: F(1,28)=7.848, p=.009$; 15-16: $F(1,28)=4.454, p=.044$. The nonstressed woodlice showed a habituation effect to the environment, reducing significantly the distance traveled between min $0-1$ and min 15$16, F(1,28)=6.519, p=.016$. In contrast, no habituation occurred among the stressed woodlice, $F(1,28)=0.995, p=$ .327. The baseline retest 5 hours later indicated full recovery, as the distance traveled was similar in the two groups, $t(28)=$ $-0.829, p=.414$.

Traveling and rearing-up behaviors are both related to exploration, although they consist of two mutually exclusive activities. Contrary to the habituation effect observed with traveling in nonstressed woodlice, there was a sensitization of the time spent rearing up over time. Figure $2 b$ indicates that a behavioral sensitization of the time spent rearing up was shown in group No-Stress between min 0 1 and $\min 15-16$, suggesting that the woodlice were more and more inclined to escape from such a hostile environment-where no humidity, no food, and no shelter was available, $F(1,28)=7.657, p=.010$. In contrast, no sensitization of the time spent rearing up occurred in group Stress; performance remained stable throughout, $F(1,28)=0.014, p=.906$.

There was an overall effect of group, $F(1,28)=$ 12.004, $p=.002$, but only a nonsignificant trend with respect to the effect of time and a near-significant interaction, time: $F(3,84)=2.608, p=.057$; Group $\times$ Time: $F(3,84)=2.735, p=.049$. The rearing-up responses of stressed and nonstressed woodlice were significantly increased in the nonstressed animals relative to the stressed animals, $10-11: F(1,28)=11.007, p=.002 ; 15-16: F(1$, $28)=10.757, p=.003$. Of note, during min $0-1$, only $20 \%$ of the stressed woodlice reared up, while they were $60 \%$ among the non-stressed woodlice. The baseline retest of these individuals 5 hours later showed similar time spent rearing up in the two groups, $t(28)=0.357, p=$ .724. The number of rearing-up behaviors was counted during $\min 0-1$ and $\min 15-16$ (see Fig. 2c). There was no overall effect of time, $F(1,27)=1.745, p=.197$. and no interaction, $F(1,27)=0.363, p=.552$, suggesting that this behavior was not sensitized-irrespective of whether the woodlice had been stressed or not. However, an overall effect of group was shown, $F(1,27)=6.095, p$ $=.020$, the stressed woodlice exhibiting a fewer number of rearing-up behaviors than the nonstressed woodlice during min $0-1, F(1,27)=6.438, p=.017$-but showed similar performance during $\min 15-16, F(1,27)=1.889$, $p=.180$.

An analysis of the effects of rotational stress on the time spent immobile during the first 2 minutes after treatment (stress or no stress) indicated that the stressed woodlice remained immobile for a longer period of time than the nonstressed woodlice (see Fig. 2d), $F(1,27)=6.571, p=$ .016). Also, the number of immobilization periods were more elevated with respect to stressed compared to nonstressed individuals, $F(1,27)=21.853, p=.000$. The values related to the number of immobilization periods in group Stress were $2.85 \pm 0.33$, and in group No-Stress were $0.87 \pm 0.25$-with a large effect size, despite low mean values $\left(\eta_{\mathrm{p}}^{2}=0.45\right)$.

\section{Familiar environment (group Pre/Post)}

The effects of stress in a familiar environment were assessed within a new group of individuals during the 2 min that preceded (PRE) and followed (POST) repeated rotation. Pre/Post comparisons indicated that rotational stress had no effect on the distance traveled (see Fig. $2 \mathrm{e}), F(1,14)=0.204, p=.659$, but significantly decreased the time spent rearing up on the compartment's walls (see Fig. 2f) $F(1,14)=28.365, p=.0001$. Accordingly, rotational stress significantly decreased the mean number of rearing-up behaviors (see Fig. 2g), $F(1$, 14) $=31.381, p=.000$. The time spent immobile was similar between the pretreatment and posttreatment conditions (see Fig. $2 \mathrm{~h}$ ), $F(1,14)=2.483, p=.137$; but note the medium effect size $\left(\eta_{\mathrm{p}}{ }^{2}=0.15\right)$. In contrast, the number of immobilizations were increased in the posttreatment relative to the pretreatment conditions, $F(1,14)=$ $28.000, p=.0001$. The pretreatment values were $0.467 \pm$ 0.133 , and the posttreatment values were $1.800 \pm 0.243$.

\section{Experiment 2}

Experiment 1 aimed to determine how stressed and nonstressed woodlice came to search for survival-related opportunities (through distance traveled and rearing-up behavior) in a novel or a familiar environment separately. In Experiment 2, the effects of rotation-induced stress on exploratory activity were examined in woodlice that were given a free choice between a novel and a familiar environment without rewards. 

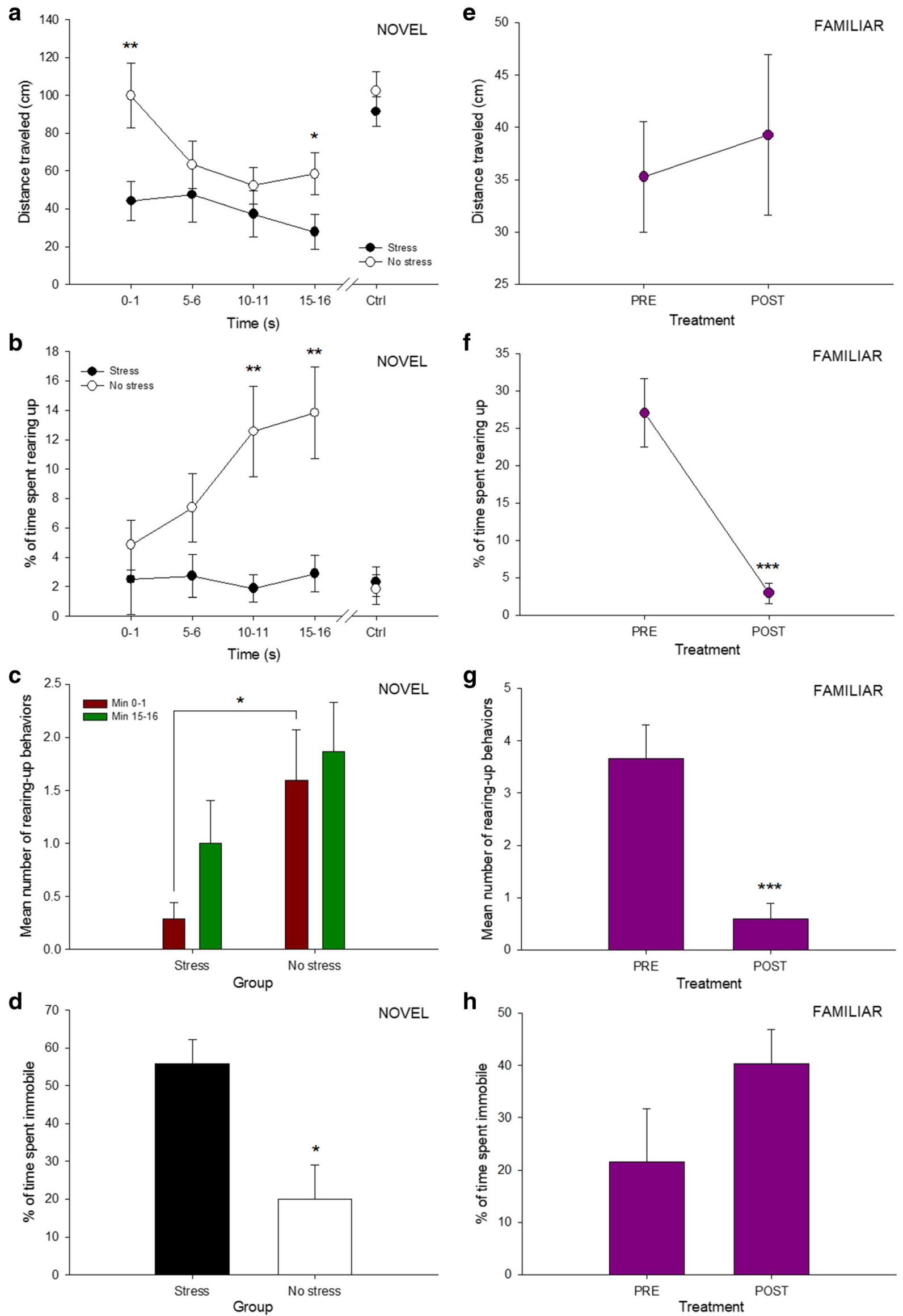
Fig. 2 Exploratory activity in woodlice, following exposure to rotational stress (Experiment 1). a Distance traveled (locomotion) in a novel environment (group Stress, $n=15$; group No-Stress, $n=15$ ). Five hours later (Ctrl), no effect of treatment could be observed. $\mathbf{b}$ Time spent rearing up in a novel environment. Five hours later $(\mathrm{Ctrl})$, the effect of treatment disappeared. c Number of rearing-up behaviors in a novel environment during the first and last 2 minutes. $\mathbf{d}$ Time spent immobile during min 0-1 in a novel environment. e Distance traveled in a familiar environment during the 2 min that preceded (PRE, min 15-16) and followed (POST) repeated rotation (group Pre/Post, $n=15$ ). $\mathbf{f}$ Time spent rearing up in a familiar environment in group Pre/Post. g Number of rearing-up behaviors in a familiar environment in group Pre/Post. $\mathbf{h}$ Time spent immobile in a familiar environment in group Pre/Post. $* p<.05$. $* * p<.01$. *** $p<$ .001. Mean and SE (Color figure online)

\section{Method}

\section{Animals and housing conditions}

A new batch of woodlice ( $N=40$; size: $10.56 \pm 0.02 \mathrm{~mm})$ was used. The animals were housed in the same conditions as in Experiment 1.

\section{Apparatus}

The woodlice were tested in the same apparatus as in Experiment 1. Here, however, the two compartments of one alley were used by the same individual to assess the behavioral effects of familiarity and of novelty. In one compartment, the floor was covered with light-brown paper whose texture was smooth. The walls consisted of an alternation of white and black vertical lines ( $4 \mathrm{~cm}$ in length and $1 \mathrm{~cm}$ in width). In the other compartment, the floor was covered with big-grained sandpaper (grain size: 60) of a light-brown color. Half of the walls were uniformly white, and the other half were uniformly back. Thus, the wall surfaces covered with a white and a black color were the same in both compartments, but these colors were distributed differently, leading to distinct visual patterns. The intermediate areas were covered with standard white paper. A removable divider was placed in the intermediate area when the animals had to be confined in one compartment.

\section{Procedure}

The woodlice were randomly assigned to two distinct groups (see further), which received the same treatment during familiarization to one of the two environments. For the familiarization phase, a removable divider was placed in the intermediate area to maintain the woodlouse in only one of the alley's compartments. One woodlouse per alley was gently placed in the center of the compartment, and it was allowed to freely move during $20 \mathrm{~min}$ in order to become familiarized with this environment. Previously, I showed that this duration was sufficient to produce strong - though not total-habituation in arenas of identical size (Anselme, 2013b, 2015). Since the procedure was a bit more complex than in Experiment 1, exposure time was longer in order to optimize the chance of success. The activity of the woodlice was video recorded during the first $2 \mathrm{~min}$ and the last $2 \mathrm{~min}$ to measure any change in exploratory behavior between the start and the end of the familiarization phase. The environments (familiar and novel) were counterbalanced across individuals.

Immediately after, in a first group (STR, $n=20$ ), the woodlice were captured using a small spoon, put in plastic cups, and manually centrifuged using the method described in Experiment 1: they underwent a series of 10-s rotations interspaced by 2-3 s for a total time of approximately $2 \mathrm{~min}$. Following this stressful experience, the removable dividers were removed from the intermediate areas, and the individuals were place in these areas, one per alley. The woodlice could freely move in one or the other compartment. Their activity was recorded for $3 \mathrm{~min}$. In a second group (CAP, $n=20$ ), after the 20 -min familiarization phase, the animals were gently moved from their location to the intermediate area by means of a bottle cap ( $3.2 \mathrm{~cm}$ in diameter). They were maintained under the cap for $2 \mathrm{~min}$, and then the cap was removed to allow them to freely move in the two compartments. This method was used to minimize the effects of stress, since the woodlice are attracted by confined spaces (Sutton, 1972). So doing, the time elapsed between the familiarization and the choice phases was similar in both groups.

The results were all analyzed by means of mixed ANOVAs with planned comparisons, and the behaviors examined were the distance traveled, the time spent rearing up, the number of rearing-up behaviors, the time spent immobile, and the number of immobilization periods. In the choice phase, these activities were measured in the familiar and in the novel environments separately.

\section{Results}

\section{Familiarization phase}

With respect to the distance traveled, overall effects of group and time, but no interaction, were observed, group: $F(1,38)=$ 12.664, $p=.001$; time: $F(1,38)=83.624, p=.000$; Group $\times$ Time: $F(1,38)=3.177, p=.083$. As depicted in Fig. 3a, there was a strong habituation effect between the first 2 and the last 2 minutes in both groups, STR: $F(1,38)=27.100, p=.000$; CAP: $F(1,38)=59.701, p=.000$. This observation was comparable with that observed in group No-Stress in Experiment 1. For unknown reason, the woodlice traveled a longer distance in group CAP than in group STR during the first 2 minutes, $F(1,38)=15.765, p=.0003$, but this significant difference was lost during the last 2 minutes, $F(1,38)=$ 2.926, $p=.095$. This suggests that running activity in the two groups of individuals was similar before starting the 


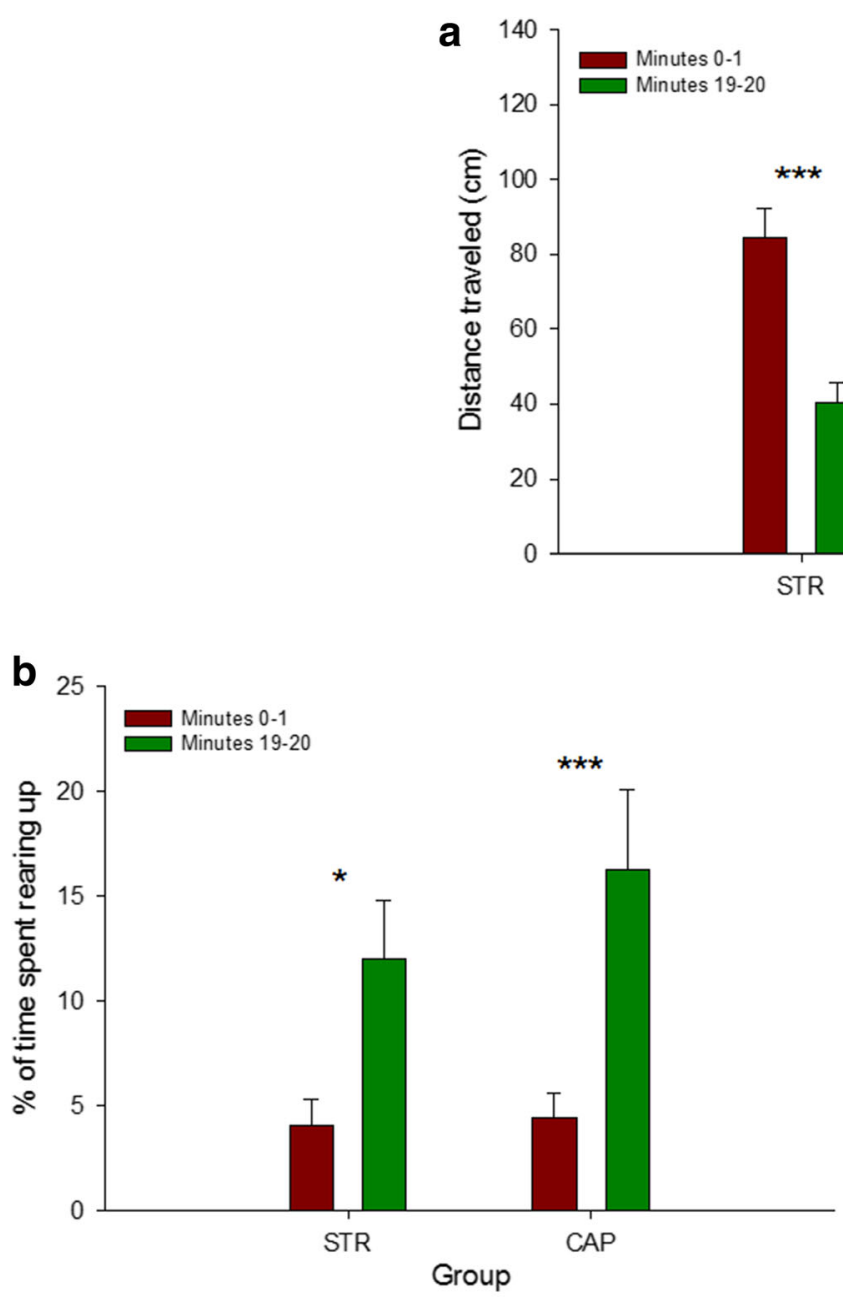

Fig. 3 Exploratory activity of woodlice during the familiarization phase (Experiment 2). a Distance traveled during min 0-1 and min 19-20. b Time spent rearing up during min $0-1$ and $\min 19-20$. c Number of rearing-up behaviors during $\min 0-1$ and $\min 19-20$. Although the

choice phase. (Note that the individuals of each group were exposed to the same treatment during this phase.)

The time elapsed had an overall effect on the time spent rearing up on a compartment's walls, time: $F(1,38)=18.189$, $p=.000$, but no effects of group and no interaction occurred, group: $F(1,38)=0.721, p=.401$; Group $\times$ Time: $F(1,38)=$ $0.724, p=.400$. In the opposite to distance traveled, familiarization had the effect of sensitizing the time spent rearing up in both groups (see Fig. 3b), STR: $F(1,38)=5.827, p=.021$; CAP: $F(1,38)=13.087, p=.0009$. This result also corroborated that found in group No-Stress in Experiment 1. In the two groups, the propensity to rear up was similar during the first 2 minutes, $F(1,38)=0.039, p=.845$, and also during the last 2 minutes, $F(1,38)=0.811, p=.373$.

Omnibus comparisons for the number of rearing-up behaviors indicated an effect of group, but no effect of time and no interaction, group: $F(1,38)=5.928, p=.020$; time: $F(1,38)=$ $0.943, p=.337$; Group $\times$ Time: $F(1,38)=0.186, p=.668$. No

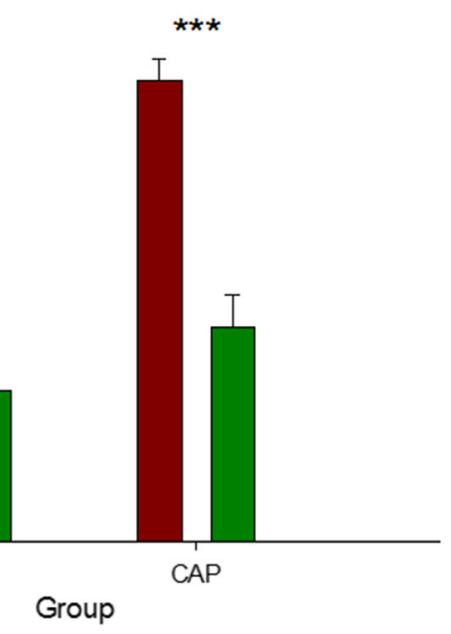

C

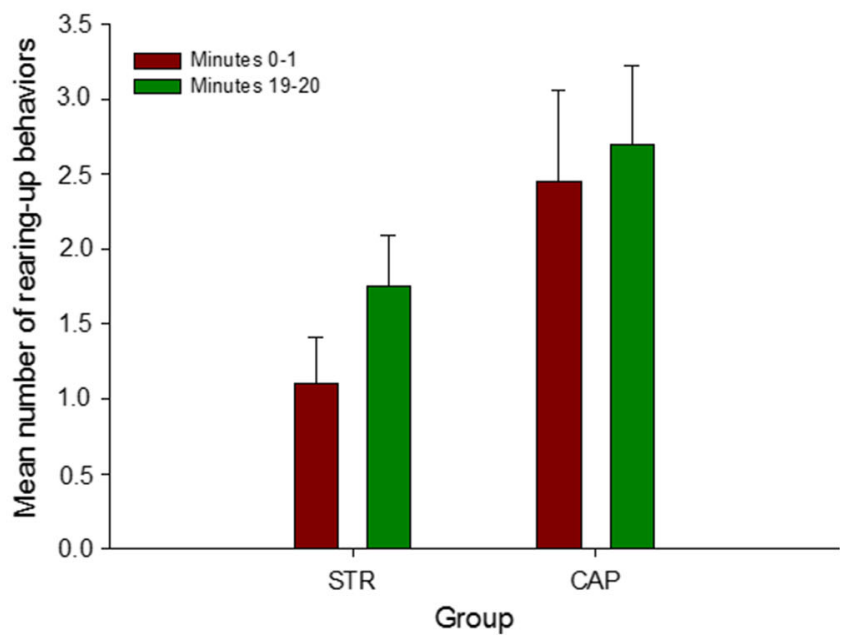

groups ( $n=20$ in each) were not formed at this stage, I showed the details of performance in each group for more transparency. $* p<.05$. *** $p<$ .001 (refer to differences between min 0-1 and min 19-20). Mean and SE (Color figure online)

sensitization of the number of rearing-up behaviors was observed (see Fig. $3 c$ ), STR: $F(1,38)=0.948, p=.327$; CAP: $F(1,38)=0.145, p=.705$. The two groups showed a similar number of rearing-up behaviors, $0-1: F(1,38)=3.831, p=$ .058 ; 19-20: $F(1,38)=2.257, p=.141$. For min $0-1$, it must be noted that the effect size was low $\left(\eta^{2}=0.09\right)$, despite large mean differences. A closer look at the distribution of those behaviors indicated that the woodlice reared up a similar number of times, except two-three individuals in group CAP (STR: 0: $10 \times, 1: 4 \times, 2: 2 \times, 3: 2 \times, 4: 2 \times$ CAP: $0: 6 \times, 1: 3 \times, 2: 3 \times, 3: 2 \times$, 4: $3 \times, 5: 1 \times, 6: 1 \times, 11: 1 \times)$, It is here important to point out that rearing-up behavior was not homogeneously distributed across individuals within a group; some individuals were more prone to show it than others. During the last 2 minutes, for example, $25 \%$ of the STR woodlice did not rear up, while $75 \%$ of them reared up a variable number of times (range: 1-6). In group CAP also, $25 \%$ of the woodlice did not rear up, while $75 \%$ of them reared up a variable number of times (range: 1-8). 


\section{Free-choice phase}

At the end of the familiarization phase, the exploratory behavior of the woodlice was equivalent in groups STR and CAP for the three parameters considered. During choice, the values related to the time spent in each compartment in group STR were $90.450 \pm 9.292$ (familiar) and $81.650 \pm 9.301$ (novel), and in group CAP were $84.900 \pm 10.673$ (familiar) and 86.500 \pm 10.883 (novel). As represented in Fig. 4a, treatment (stress or no stress) did not impact the distance traveled by the woodlice. There was no group difference, no effect of the environment, and no interaction between these two variables, group: $F(1,38)=0.204, p=.654$; environment: $F(1,38)=$ $0.012, p=.913$; Group $\times$ Environment: $F(1,38)=0.303, p=$ .585 . This result is compatible with the absence of effect in the familiar environment, but not with the decrease in running activity in the novel environment observed in Experiment 1. It might be a consequence of the habituation process that occurred in the previous phase, which was absent in the novel environment in Experiment 1.

Group differences were visible relative to rearing-up behaviors - whose occurrence had been sensitized rather than habituated (see Fig. 4b), $F(1,38)=8.418, p=.006$. Specifically, the STR woodlice spent less time rearing up on the walls than the CAP woodlice, irrespective of the type of environment, familiar: $F(1,38)=6.380, p=.016$; novel: $F(1$, $38)=5.829, p=.021$. Accordingly, the effects of environment and interaction were nonsignificant, environment: $F(1,38)=$ $0.354, p=.555$; Group $\times$ Environment: $F(1,38)=0.475, p=$ .495 .

The same pattern of results was also shown with respect to the number of rearing-up behaviors (see Fig. 4c), group: $F(1$, $38)=9.387, p=.004$; environment: $F(1,38)=0.027, p=$ .869 ; Group $\times$ Environment: $F(1,38)=0.246, p=.623$. Here, also, there was a significant decrease in activity among the STR woodlice compared with the CAP woodlice in each a

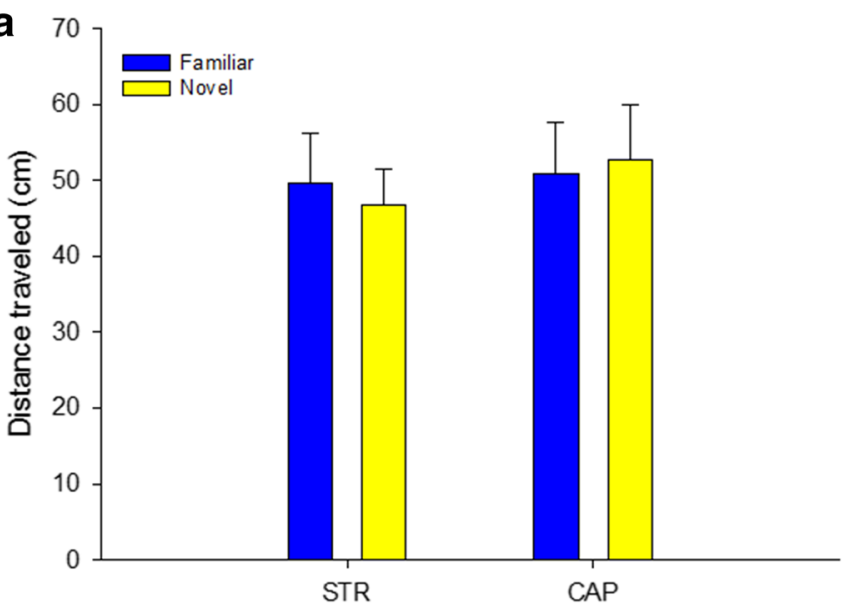

C

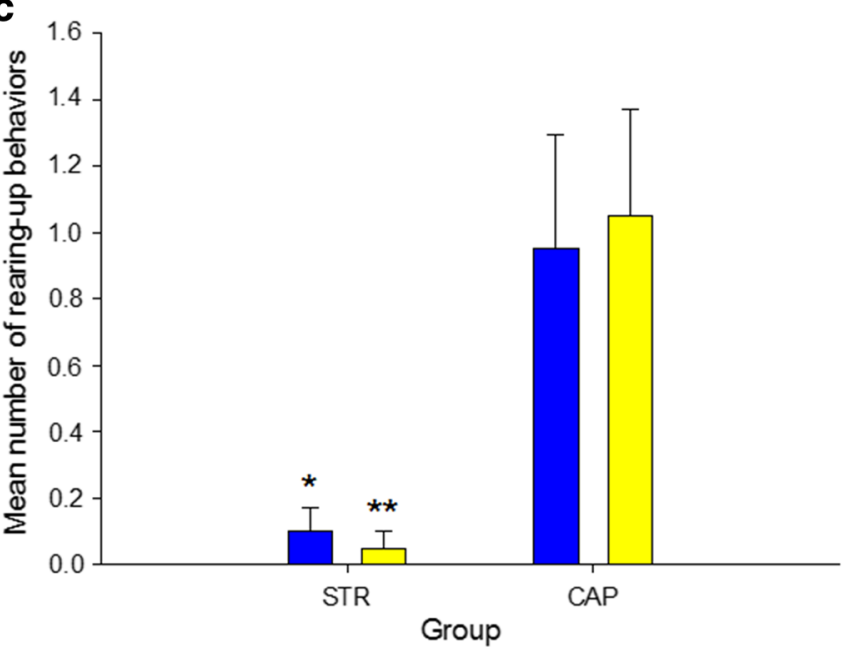

Fig. 4 Exploratory activity of woodlice during the choice phase (Experiment 2). a Distance traveled in groups STR and CAP in each environment (familiar and novel). b Time spent rearing up in the two environments. c Number of rearing-up behaviors in the two
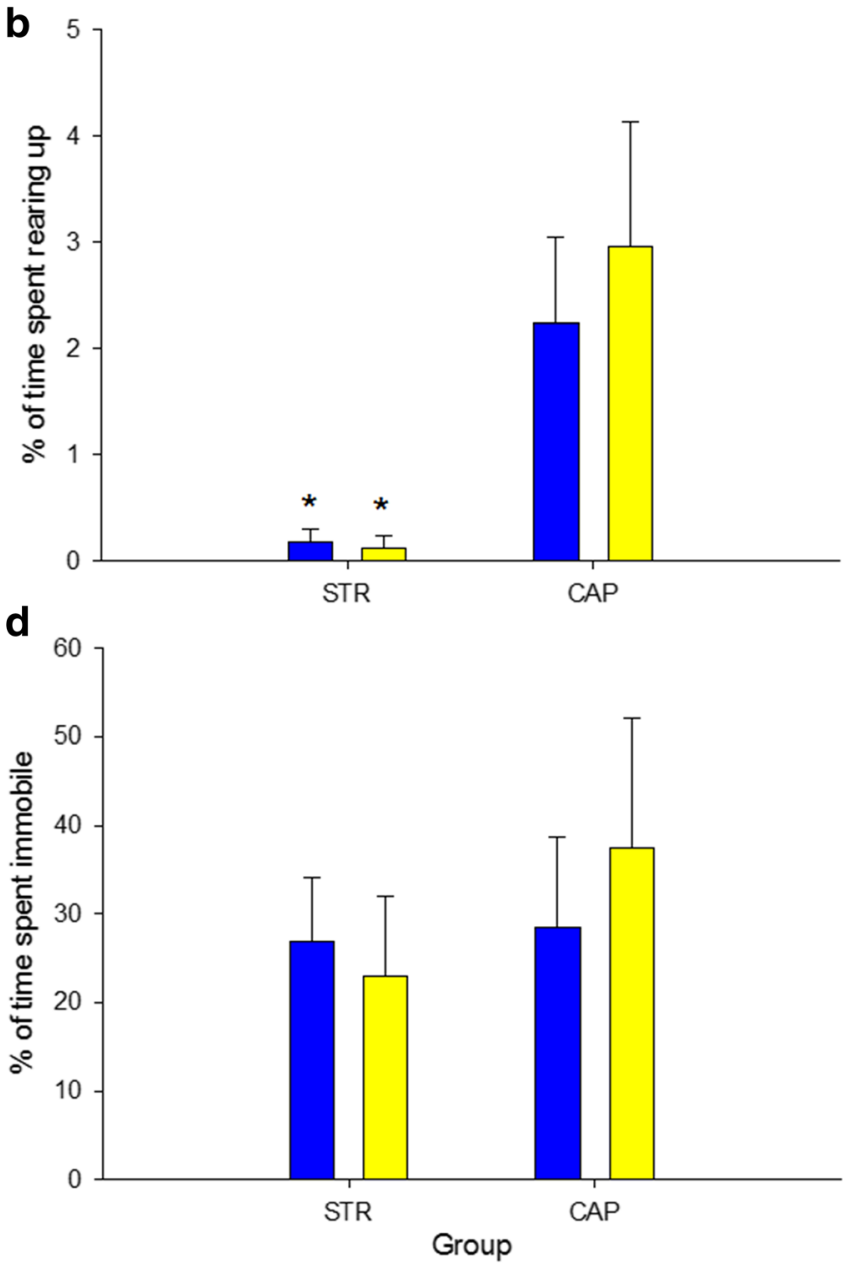

environments. $\mathbf{d}$ Time spent immobile in the two environments. For each group, $n=20 . * p<.05$. $* * p<.01$ (relative to their CAP-group counterpart). Mean and SE (Color figure online) 
environment, familiar: $F(1,38)=5.873, p=.020$; novel: $F(1$, $38)=9.524, p=.004$. During the choice phase, $85 \%$ of the STR woodlice did not rear up, while only $15 \%$ of them reared up once. In group CAP, $50 \%$ of the woodlice did not rear up, and $50 \%$ of them reared up a variable number of times (range: $1-5)$.

There was no evidence that the STR woodlice spent more time immobile than the CAP woodlice in either environments (see Fig. 4d), group: $F(1,38)=0.839, p=0.365$; environment: $F(1,38)=0.045, p=.834$; Group $\times$ Environment: $F(1,38)=$ $0.276, p=.602$. Also, the number of immobilization periods was equivalent in both groups, irrespective of the environment, group: $F(1,38)=0.352, p=.556$; environment: $F(1$, $38)=3.177, p=.083$; Group $\times$ Environment: $F(1,38)=$ $0.127, p=.723$. The values related to the number of immobilization periods in group STR were $1.30 \pm 0.26$ (familiar) and $0.90 \pm 0.27$ (novel), and in group CAP were $1.25 \pm 0.35$ (familiar) and $0.65 \pm 0.15$ (novel).

Given that the woodlice from both groups performed similarly in the familiar and the novel environment, it was useful to compare the time spent in each of them. As expected, there was no effect of group, $F(1,38)=0.110, p=.743$, no effect of environment, $F(1,38)=0.060, p=.801$, and no interaction, $F(1,38)=0.130, p=.716$.

\section{Discussion}

This study demonstrates that repeated animal rotation-a mechanical disturbance that is likely to induce a physiological stress response-has some behavioral effects in the woodlouse, P. scaber. In a novel environment (Experiment 1), repeated rotation decreases the distance traveled and the time spent rearing up, and increases the number and the duration of immobilizations. In a familiar environment (Experiment 1), the operation has no effects on the distance traveled, decreases the number and the duration of rearing-up behaviors, and increases the number (but not the duration) of immobilizations. During free choice between a novel and a familiar environment (Experiment 2), repeated rotation has no effects on the distance traveled, decreases the number and the duration of rearing-up behaviors, and does not influence immobilizations. Performance was independent of the type of environment.

These results suggest that habituated behaviors (distance traveled) are not affected by rotational stress in the presence of a familiar environment, while sensitized behaviors (time spent rearing up) are reduced by rotational stress in all environments. Note that the number of rearing-up behaviors is only decreased in the presence of a familiar environment. In contrast, immobilizations are mainly increased when the environment is novel. The behavioral patterns observed in Experiment 2 are very similar to those observed in the familiar environment of Experiment 1-apart from the impact of rotational stress on the number of immobilizations. This may indicate that proximity with familiar patterns protects against the stressful experience that novelty represents. This protective effects of familiarity is particularly visible relative to habituated behaviors (distance traveled), and also to potential indicators of stress (duration of immobilizations).

Why was locomotion unchanged in the stressed woodlice familiarized to one compartment? Habituation denotes a decrease in responding to repeated or prolonged stimulation (e.g., Leussis \& Bolivar, 2006); it is a very basic learning process, universally met throughout the animal kingdom. Given the inhibitory effect of rotations on locomotion in an entirely novel environment and the fact that habituation did not abolish locomotion at the end of the familiarization phase in Experiments 1 and 2, a reduction in the distance traveled was expected when familiar patterns were present. The insensitivity of locomotion to the stress episode suggests that preexposure to the environment had some antistress protective effects on habituated but not on sensitized exploratory behaviors in P. scaber. One related element that supports this interpretation comes from the assessment of immobilizations (duration), a typical reaction ("quiescence") of woodlice and of the individuals of other species to mechanical stimulation (e.g., Acheampong \& Mitchell, 1997; King \& Leaich, 2006; Miyatake, 2001). The time spent immobile was equivalent in stressed and nonstressed woodlice after preexposure in Experiments 1 and 2, while it was longer in stressed than in nonstressed individuals without preexposure in Experiment 1. Provided that the duration of immobilizations is a reliable behavioral indicator of stress, the absence of effects on locomotion suggests that preexposure partly reduced the rotational-stress response.

The protective effect of habitual situations on stress reactions has long been studied in animal and human psychology (e.g., Barlow, 1988; Craske, Glover, \& DeCola, 1995; Rescorla, 1969; Williams, Overmier, \& LoLordo, 1992). It is a consequence of conditioned inhibition, a Pavlovian conditioning process in which an individual learns to predict the absence of an unconditioned stimulus - here, a stressor. The individual's ability to predict safety is learned from exposure to contextual cues never associated with the stressor previously. For example, periods of predictable safety (breaks at work, parental care, food consumption, etc.) can substantially reduce stress in people because they have learned that bad things do not happen in their presence (Domjan, 2007). Inhibitory conditioning has been shown in honeybees (Giurfa et al., 1999; Gould, 1986; but see Couvillon, Ablan, \& Bitterman, 1999), but, to my knowledge, this process had never been highlighted in crustaceans. More thorough investigation is necessary to determine why the protective effects of familiarity affected habituated, not sensitized, behaviors. In addition, it is unclear why conditioned inhibition of the distance traveled occurred 
similarly in the familiar and the novel environments. It is unlikely that the two environments were too small in size to observe context-specific effects (e.g., see Anselme, 2015). More likely is the hypothesis that the partial habituation effects observed after 20 minutes were not sufficient for the woodlice to acquire a full knowledge of their environment. The familiar environment was certainly more familiar than the novel one (as the habituation data suggest), but not necessarily entirely predictable for those animals. This means that some exploration could still be expected in the familiar environment, while its proximity with the novel environment was able to reduce novelty-induced stress.

One potential limitation of this study is the absence of a physiological measure of the stress response in woodlice. Stressful events are known to reduce biogenic monoamines in several invertebrate species (Bateson et al., 2011; Ottaviani, Caselgrandi, Franchini, \& Franceschi, 1993; Ottaviani, Caselgrandi, Petraglia, \& Franceschi, 1992), and the crustacean hyperglycemic hormone has similar effects to those of cortisol and corticosterone in vertebrates (Elwood et al., 2009). Here, it can only be assumed that rotations had stressrelated effects on the physiology of the woodlice. However, the evidence that repeated rotation significantly reduced their overall propensity to explore and increased immobilization time in a novel environment not only is a sign that this event was perceived by those animals but also that it was averse (Schmalfuss, 1984). Given the limited allocation of time to exploration in woodlice (Broly et al., 2013), they are likely to do this activity after a prolonged period under a shelter, when they have not encountered any mechanical stressor for a while. Another potential limitation is that the $2 \mathrm{~min}$ of interruption between familiarization and free choice in Experiment 2 could have caused some forgetting of the environment. Although there is evidence for spatial memory in the desert isopod Hemilepistus reaumuri (Hoffmann, 1983, 1985), no data are available with respect to P. scaber. However, the hypothesis of a significant memory loss is unlikely hereotherwise, the distance traveled should have increased in group CAP (control), at the level reached at the beginning of the familiarization phase (see Ctrl retest in Experiment 1).

The differences observed between min 15-16 in group No-Stress and min 15-16 in the PRE phase of group Pre/ Post may appear surprising (cf. Fig. 2a vs. 2e, and Fig. 2b vs. 2f). Indeed, at this stage, the woodlice received identical training. It is likely that these differences resulted from the fact that the woodlice were not tested at the same period of the year. They were tested in June or July in group No-Stress (and also in group Stress), while they were tested mid-October in group Pre/Post. They could experience the absence of food or shelter differently in summer and in autumn, and this might have had an impact on their behavior. However, the effects of rotational stress on locomotion and rearing up were coherent from one experiment to the other; the amount of responses in each group is unimportant here.

Finally, a growing number of studies shows an influence of interindividual differences ("temperament") on behavioral performance among invertebrate species, including woodlice (e.g., Devigne, Broly, \& Deneubourg, 2011; Pamir et al., 2011; Planas-Sitjà, Deneubourg, Gibon, \& Sempo, 2015; Pogson, 2016; Tuf, Drábková, \& Šipoš, 2015): Some individuals seem to be more prone to move and explore than others. I would like to note that such differences were also observed here. The proportion of stressed and nonstressed woodlice that reared up was similar in the two experiments, but each group contained individuals that displayed that behavior and others that did not. Contrary to a widespread idea, behavioral variability is not limited to "higher" vertebrates but also exists in phylogenetically distant species.

\section{References}

Acheampong, S., \& Mitchell, B. K. (1997). Quiescence in the Colorado potato beetle, Leptinotarsa decemlineata. Entomologica Experimentalis et Applicata, 82, 83-89.

Adamo, S. A., \& Baker, J. L. (2011). Conserved features of chronic stress across phyla: The effects of long-term stress on behavior and the concentration of the neurohormone octopamine in the cricket, Gryllus texensis. Hormones and Behavior, 60, 478-483.

Alcaro, A., Panksepp, J., \& Huber, R. (2011). D-amphetamine stimulates unconditioned exploration/approach behaviors in crayfish: Towards a conserved evolutionary function of ancestral drug reward. Pharmacology, Biochemistry and Behavior, 99, 75-80.

Anselme, P. (2013a). Preference for rich, random tactile stimulation in woodlice (Porcellio scaber). Learning and Motivation, 44, 326336.

Anselme, P. (2013b). Sensitivity to tactile novelty in the terrestrial isopod, Porcellio scaber. Behavioural Processes, 92, 52-59.

Anselme, P. (2015). Enhanced exploratory activity in woodlice exposed to random visuo-tactile patterns. Learning and Motivation, 50, 4858.

Bardo, M. T., Neisewander, J. L., \& Pierce, R. C. (1989). Noveltyinduced place preference behavior in rats: Effects of opiate and dopaminergic drugs. Pharmacology, Biochemistry, and Behavior, $32,683-689$.

Barlow, D. H. (1988). Anxiety and its disorders. New York, NY: Guilford Press.

Barron, A. B., \& Klein, C. (2016). What insects can tell us about the origins of consciousness. Proceedings of the National Academy of Science, 113, 4900-4908.

Bateson, M., Desire, S., Gartside, S. E., \& Wright, G. A. (2011). Agitated honeybees exhibit pessimistic cognitive bias. Current Biology, 21, 1070-1073.

Broly, P., Deneubourg, J. L., \& Devigne, C. (2013). Benefits of aggregation in woodlice: A factor in the terrestrialization process? Insectes Sociaux, 60, 419-435.

Cabib, S., \& Puglisi-Allegra, S. (2012). The mesoaccumbens dopamine in coping with stress. Neuroscience and Biobehavioral Reviews, 36, 79-89.

Couvillon, P. A., Ablan, C. D., \& Bitterman, M. E. (1999). Exploratory studies of inhibitory conditioning in honeybees (Apis mellifera). 
Journal of Experimental Psychology: Animal Behavior Processes, $25,103-112$.

Craske, M. G., Glover, D., \& DeCola, J. (1995). Predicted versus unpredicted panic attacks: Acute versus general distress. Journal of Abnormal Psychology, 104, 214-223.

Devigne, C., Broly, P., \& Deneubourg, J.-L. (2011). Individual preferences and social interactions determine the aggregation of woodlice. PLOS ONE, 6, e17389.

Domjan, M. (2007). The principles of learning and behavior. New York, NY: Wadsworth.

Drahokoupilová, T., \& Tuf, I. H. (2012). The effect of external marking on the behaviour of the common pill woodlouse Armadillidium vulgare. Zookeys, 176, 145-154.

Elwood, R.W., Barr, S., \& Patterson, L. (2009). Pain and stress in crustaceans? Applied Animal Behaviour Science, 118, 128-136.

Giurfa, M., Hammer, M., Stache, S., Stollhoff, N., Muller-Deisig, N., \& Mizyricki, C. (1999). Pattern learning by honey bees: Conditioning procedure and recognition strategy. Animal Behaviour, 57, 315-324.

Gould, J. L. (1986). Pattern learning by honey bees. Animal Behaviour, 34, 990-997.

Grønli, J., Murison, R., Fiskea, E., Bjorvatn, B., Sørensena, E., Portas, C. M., \& Ursin, R. (2005). Effects of chronic mild stress on sexual behavior, locomotor activity, and consumption of sucrose and saccharine solutions. Physiology and Behavior, 84, 571-577.

Harris, R. B. S., Zhou, J., Youngblood, B. D., Smagin, G. N., \& Ryan, D. H. (1998). Failure to change exploration or saccharine preference in rats exposed to chronic mild stress. Physiology and Behavior, 63, 91-100.

Hassall, M. (1996). Spatial variation in favourability of a grass heath as a habitat for woodlice (Isopoda: Oniscidea). Pedobiologia, 40, 514 528.

Heyser, C. J., \& Chemero, A. (2012). Novel object exploration in mice: Not all objects are created equal. Behavioural Processes, 89, 232 238.

Hoese, B. (1989). Morphological and comparative studies on the second antennae of terrestrial isopods. In F. Ferrara, R. Argano, C. Manicastri, H. Schmalfuss, \& S. Taiti (Eds.), Proceedings of the second symposium on the biology of terrestrial isopods (pp. 127152). Urbino, Italy: Monitore Zoologico Italiano.

Hoffmann, G. (1983). The search behavior of the desert isopod Hemilepistus reaumuri as compared with a systematic search. Behavioral Ecology and Sociobiology, 13, 93-106.

Hoffmann, G. (1985). The influence of landmarks on the systematic search behaviour of the desert isopod Hemilepistus reaumuri. Behavioral Ecology and Sociobiology, 17, 335-348.

Holdich, D. M., \& Lincoln, R. J. (1974). An investigation of the surface of the cuticle and associated sensory structures of the terrestrial isopod, Porcellio scaber. Journal of Zoology, 172, 469-482.

Hornung, E. (1991). Isopod distribution in a heterogeneous grassland habitat. In P. Juchault \& J. Mocquard (Eds.), The biology of terrestrial isopods III: Proceedings of the third international symposium on the biology of terrestrial isopods (pp. 73-79). Poitiers, France: University Press.

Hornung, E. (2011). Evolutionary adaptation of oniscidean isopods to terrestrial life: Structure, physiology, and behavior. Terrestrial Arthropod Reviews, 4, 95-130.

Huber, R., Panksepp, J. B., Nathaniel, T., Alcaro, A., \& Panksepp, J. (2011). Drug-sensitive reward in crayfish: An invertebrate model system for the study of seeking, reward, addiction, and withdrawal. Neuroscience and Biobehavioral Reviews, 35, 1847-1853.

Hughes, R. N. (1968). Effects of age on novelty reactions and exploration in rats. Quarterly Journal of Experimental Psychology, 20, 189 192

Hughes, R. N. (2007). Neotic preferences in laboratory rodents: issues, assessment and substrates. Neuroscience and Biobehavioral Reviews, 31, 441-464.
Jander, R. (1997). Macroevolution of a fixed action pattern for learning: The exploratory flights of bees and wasps. In G. Greenberg \& E. Tobach (Eds.), Comparative psychology of invertebrates: The field and laboratory study of insect behavior (pp. 79-99). New York, NY: Garland Publishing.

Kalueff, A. V., Keisala, T., Minasyan, A., Kuuslahti, M., \& Tuohimaa, P. (2006). Temporal stability of novelty exploration in mice exposed to different open field tests. Behavioural Processes, 72, 104-112.

King, B. H., \& Leaich, H. R. (2006). Variation in propensity to exhibit thanatosis in Nasonia vitripennis (Hymenoptera: Pteromalidae). Journal of Insect Behavior, 19, 241-249.

Leussis, M. P., \& Bolivar, V. J. (2006). Habituation in rodents: A review of behavior, neurobiology, and genetics. Neuroscience and Biobehavioral Reviews, 30, 1045-1064.

Mailleux, A.-C., Devigne, C., Deneubourg, J.-L., \& Detrain, C. (2010). Impact of starvation on Lasius niger's exploration. Ethology, 116, $248-256$.

Mason, G. J. (2011). Invertebrate welfare: Where is the real evidence for conscious affective states? Trends in Ecology \& Evolution, 26, 212 213.

Mather, J. A., \& Anderson, R. C. (1999). Exploration, play and habituation in octopuses (Octopus dofleini). Journal of Comparative Psychology, 113, 333-338.

Mendl, M., Paul, E. S., \& Chittka, L. (2011). Animal behaviour: Emotion in invertebrates? Current Biology, 21, R463-R465.

Meyer-Rochow, V. B. (2001). The crustacean eye: Dark/light adaptation, polarization sensitivity, flicker fusion frequency, and photoreceptor damage. Zoological Science, 18, 1175-1197.

Miyatake, T. (2001). Effects of starvation on death-feigning in adults of Cylas formicarius (Coleoptera: Brentidae). Annals of the Entomological Society of America, 94, 612-616.

Nilsson, D.-E., \& Nilsson, H.L. (1981). A crustacean compound eye adapted for low light intensities (Isopoda). Journal of Comparative Physiology, 143, 503-510.

Ottaviani, E., Caselgrandi, E., Franchini, A., \& Fransceschi, C. (1993). CRF provokes the release of norepinephrines by hemocytes of Viviparus ater (Gasteropoda, Prosobranchia): Further evidence in favour of the evolutionary hypothesis of the "mobile immunebrain". Biochemical and Biophysical Research Communications, 193, 446-452.

Ottaviani, E., Caselgrandi, E., Petraglia, F., \& Franceschi, C. (1992). Stress response in the freshwater snail Planorbarius corneus (L.) (Gasteropoda, Pulmonata): Interaction between CRF, ACTH and biogenic amines. General and Comparative Endocrinology, 87, 354-360.

Ottaviani, E., \& Franceschi, C. (1996). The neuroimmunology of stress from invertebrates to man. Progress in Neurobiology, 48, 421-440.

Pamir, E., Chakroborty, N. K., Stollhoff, N., Gehring, K.B., Antemann, V., Morgenstern, L., ... Nawrot, M. P. (2011). Average group behavior does not represent individual behavior in classical conditioning of the honeybee. Learning and Memory, 18, 733-741.

Planas-Sitjà, I., Deneubourg, J.-L., Gibon, C., \& Sempo, G. (2015). Group personality during collective decision-making: A multilevel approach. Proceedings of the Royal Society B, 282. doi: https://doi.org/10.1098/rspb.20142515

Pogson, M. (2016). Simulation of invertebrate aggregation shows the importance of stable personality over diversity in consensus decision-making. PLoS ONE, 11, e0165082.

Powell, C. V. L., \& Halcrow, K. (1982). The surface microstructure of marine and terrestrial isopoda (Crustacea, Peracarida). Zoomorphology, 101, 151-164.

Pravosudov, V. V. (2003). Long-term moderate elevation of corticosterone facilitates avian food-caching behaviour and enhances spatial memory. Proceedings of the Royal Society B, 270, 2599-2604.

Rescorla, R. A. (1969). Pavlovian conditioned inhibition. Psychological Bulletin, 72, 77-94. 
Romana-Souza, B., Otranto, M., Vieira, A. M., Filgueiras, C. C., Fierro, I. M., \& Monte-Alto-Costa, A. (2010). Rotational stress-induced increase in epinephrine levels delays cutaneous wound healing in mice. Brain, Behavior, and Immunity, 24, 427-437.

Schmalfuss, H. (1984). Eco-morphological strategies in terrestrial isopods. In S. L. Sutton \& D. M. Holdich (Eds.), The biology of terrestrial isopods (pp. 49-64). Oxford, UK: Clarendon Press.

Schmalfuss, H. (1998). Evolutionary strategies of the antennae in terrestrial isopods. Journal of Crustacean Biology, 18, 10-24.

Stefano, G. B., Cadet, P., Zhu, W., Rialas, C. M., Mantione, K., Benz, D., ... Slingsby, B. (2002). The blueprint for stress can be found in invertebrates. Neuroendocrinology Letters, 23, 85-93.

Strekalova, T., Spanagel, R., Bartsch, D., Henn, F. A., \& Gass, P. (2004). Stress-induced anhedonia in mice is associated with deficits in forced swimming and exploration. Neuropsychopharmacology, 29, 2007-2017.

Sutton, S. (1972). Woodlice. London, UK: Ginn.

Tuf, I. H., Drábková, L., \& Šipoš, J. (2015). Personality affects defensive behaviour of Porcellio scaber (Isopoda, Oniscidea). Zookeys, 515, 159-171.

Tuf, I. H., \& Jeřábková, E. (2008). Diurnal epigeic activity of terrestrial isopods (Isopoda: Oniscidea). In M. Zimmer, F. Charfi-
Cheikhrouha, \& S. Taiti (Eds.), Proceedings of the international symposium of terrestrial isopod biology ISTIB-07 (pp. 167-172). Aachen, Germany: Shaker Verlag.

Williams, D. A., Overmier, J. B., \& LoLordo, V. M. (1992). A reevaluation of Rescorla's early dictums about Pavlovian conditioned inhibition. Psychological Bulletin, 111, 275-290.

Winkler, H., \& Leisler, B. (1999). Exploration and curiosity in birds: Functions and mechanisms. In N. J. Adams \& R. H. Slotow (Eds.), Proceedings of the 22th International Ornithological Congress, Durban (pp. 915-932). Johannesburg: BirdLife South Africa.

Zhukovskaya, M. I. (2014). Grooming behavior in American cockroach is affected by novelty and odor. The Scientific World Journal doi: https://doi.org/10.1155/2014/329514

Ziegler, A., \& Altner, H. (1995). Are the most numerous sensilla of terrestrial isopods hygroreceptors? Ultrastructure of the dorsal tricorn sensilla of Porcellio scaber. Cell and Tissue Research, 282, $135-145$.

Zimmer, M., \& Topp, W. (1997). Does leaf litter quality influence population parameters of the common woodlouse, Porcellio scaber (Crustacea: Isopoda)? Biology and Fertility of Soils, 24, 435-441. 